\title{
A Cross-Cultural Study of Gifted Students' Scientific, Societal, and Moral Questions Concerning Science
}

\author{
Kirsi Tirri,, ${ }^{1}$ Sakari Tolppanen, ${ }^{2}$ Maija Aksela, ${ }^{2}$ and Elina Kuusisto ${ }^{1}$ \\ ${ }^{1}$ Department of Teacher Education, University of Helsinki, P.O. Box 9, 00014 Helsinki, Finland \\ ${ }^{2}$ The Unit of Chemistry Teacher Education, Department of Chemistry, University of Helsinki, P.O. Box 55, 00014 Helsinki, Finland
}

Correspondence should be addressed to Kirsi Tirri, kirsi.tirri@helsinki.fi

Received 24 February 2012; Revised 25 June 2012; Accepted 17 July 2012

Academic Editor: Liam Gearon

Copyright ( $) 2012$ Kirsi Tirri et al. This is an open access article distributed under the Creative Commons Attribution License, which permits unrestricted use, distribution, and reproduction in any medium, provided the original work is properly cited.

\begin{abstract}
This study investigated the number and nature of gifted female and male students' scientific, societal, and moral questions concerning science. The participants $(N=658)$ of this study were 16-19-year-old international students from 55 countries and two continents, Asia and Europe. They applied to participate in the Millennium Youth Camp held in 2011 in Finland. The students came from scientifically and mathematically oriented schools, and they had shown an interest towards science through competitions, school success, and their own research. The students were asked to formulate questions they would like to get answers to during the camp. The nature and number of the students' questions were analyzed with qualitative and quantitative content analysis. The results showed that the boys asked more scientific questions than the girls, and the girls asked more societal questions than the boys. The students asked less questions about morality than scientific or societal questions. The most common questions about morality were related to pollution and fresh air, environmental problems, and water protection. The results point to the need for teachers to teach socioscientific issues and discuss moral questions related to science.
\end{abstract}

\section{Introduction}

In this study we explored the number and nature of moral questions and compared them with the scientific and societal questions asked. The questions were presented by international high school students gifted in science. The students $(N=658)$ came from Europe and Asia and were identified gifted because most of them came from scientific schools or classes, many had done well in national or international science competitions, won scholarships and prizes as well as had good school grades. All of the students applied to join the Millennium Youth Camp held in 2011 in Finland [1]. The camp is aimed at 16-19-year-old students gifted in science. The students in this study chose to study one of the camp's environmental themes in more detail: climate change, renewable energy and resources, and water. All three themes can be explored from a scientific, societal, or moral perspective. In the application form, the students were asked to present three questions related to their chosen theme, which they wanted an answer during the camp.

We analyzed the students' questions and divided them into three different categories: scientific, societal, and moral.
Our aim was to explore the nature of the questions that the students had asked and the possible cross-cultural and gender differences in these questions. Furthermore, our aim was to contribute to the discussion on science education as moral education. In addition to scientific knowledge, science education deals with societal issues and ethical dilemmas [2]. Excellence in science needs to be combined with ethics to serve humankind in the best possible way [3]. Therefore, moral sensitivity in science includes the skill of being able to identify a moral question in a science domain. Previous research has revealed a close relationship between morality and socioscientific issues and also advocated the need for addressing ethical aspects in science education $[4,5]$. In this study we explored the nature of the moral, scientific, and societal questions the gifted students identified.

\section{Socioscientific Issues in Science Education}

As science interacts with many different aspects of human activity, such as economics, the environment, technology, culture, and social issues, science education should not only 
focus on scientific facts, but on the interactions of these different spheres. For instance, many issues, such as the use of renewable resources, are both scientific and societal in nature. Unlike the traditional problems faced in a science class, these so-called socioscientific issues do not have one clear answer that can be found at the back of the textbook. Moreover, they may not have, as there may not be, a right answer at all [6].

Socioscientific issues, such as global warming and the use of renewable resources, two of the themes of the Millennium Youth Camp, often contain controversial ideas and do not necessarily have generally accepted viewpoints, as people may look at different aspects of the issue [7]. When engaging students with controversial socioscientific issues, students need to be critical, skeptical, and open to new ideas in order to deal with these problems. In order to reach these goals of scientific literacy, Zeidler et al. [8] have argued that it is necessary to include moral issues and discussion in the science curriculum.

As environmental issues deal with many moral and ethical aspects, environmental education could be a means to reach this goal. A step towards increasing environmental education has already been taken as researchers have suggested moving beyond STS (science, technology, and society) curricula towards STSE (science, technology, society, and environment) curricula in order to pay more attention to the moral aspects of socioscientific issues [4].

Already in 1972, at a conference held by the United Nations, it was decided that schools should emphasize formal and informal environmental education more. As a consequence, environmental education is seen as key in many national curricula, for example in Finland and the USA $[9,10]$. Furthermore, the OECD [11] has been discussing the importance of environmental education and has set goals to increase public knowledge on environment issues. The main goals are to increase knowledge on the causes and effects of environmental pollutants, climate change, and the use of renewable resources. Another important goal is to increase students' knowledge on how to protect the environment [12]. For instance, by discussing environmental issues with students, educators can introduce "real-life" problems to their students. Moreover, scientific knowledge then becomes part of the currency of such discussions and helps students to make decisions regarding societal issues that are relevant to their lives [13].

\section{Moral Education and Gifted Students}

We know from earlier empirical research that intelligence tends to correlate with high levels of moral reasoning [14, 15]. However, the relationship between intelligence and morality is a very complex one and needs more detailed study $[16,17]$. According to Bebeau et al. [18], morality is built upon four basic components. These include moral sensitivity, moral judgment, moral motivation, and moral character. The components of moral sensitivity, moral motivation, and moral character have been less studied than the component of moral judgment.
Tirri [3] argues that skills in moral judgment and especially in moral sensitivity are necessary in order to combine excellence with ethics. High-ability students have shown to be superior in moral judgment when compared to averageability students. However, high academic ability does not always predict high moral judgment [14]. Morality includes other components as well, such as sensitivity, motivation, and character. According to Muriel Bebeau et al. [18], moral sensitivity is about the awareness of how our actions affect other people. Thus, without possessing a moral sensitivity it would be difficult to see the kind of moral issues that are involved in science. However, to respond to a situation in a moral way, a scientist must be able to perceive and interpret events in a way that leads to ethical action. A morally sensitive scientist notes various situational cues and is able to visualize several alternative actions in response to that situation. He or she draws on many aspects skills, techniques, and components of interpersonal sensitivity. These include taking the perspective of others (role taking), cultivating empathy for others, and interpreting a situation based on imagining what might happen and who might be affected.

The students in this study come from a selected group of international students gifted in science. Their main interest is in science and academic affairs and technology based on humane values. However, in addition to scientific questions, science education has great potential for addressing questions related to globalization, morality, and societal issues $[3,4,8,9]$. Science education is also moral education and it deals with questions of a good life and future. Science education gives teachers opportunities to educate the youth in terms of their life perspectives including their world-view and ethics. It should offer tools for scientific argumentation and moral judgement [15]. Moral sensitivity includes skills in identifying and asking moral questions related to science and research done in that area. It also includes social skills in sharing and working in teams to solve scientific problems.

\section{Young People's Perspectives and Questions Related to the Future}

Earlier comparative research conducted in different countries has revealed remarkable differences in perspectives for the future of young people and also in the questions they ask about the future [19-22]. In the study by Ziebertz and Kay [19], a total of 8,096 young people with an average age of between 17 and 18, who attended good academic secondary schools in nine European countries, were investigated. The researchers wanted to explore the views of these future opinion formers. The authors argued that the young people in their study were likely to be in a position to exert social and cultural influence and occupy important positions. Their research findings showed that these young people differed in the degree to which they had positive or negative views about the future. In Germany, for example, young people were the most pessimistic when it came to discussing their prospects in life. Similarly in England and the Netherlands pessimism figured in the top three attitudes expressed about the future. This finding means that young people in Europe assess their 
personal chances for the future as being quite bad. However, youth from the Nordic countries, Finland, and Sweden had a more positive attitude and trusted themselves to be masters of their own future [19].

Studies on gifted learners' questions have demonstrated some culture-invariant trends. Gifted learners in the USA, Hong Kong, and Finland were more concerned than average ability learners about large global issues [23]; a result that was also obtained in prior studies $[20,24]$. This lends further support for curriculum for gifted learners on global issues of concern to these students. In addition, this appears to be true of all three countries in the study.

In another cross-cultural study, preadolescents' questions about the future were investigated [21]. The students $(N=$ 975) came from four countries, namely, Finland, the United States, Hong Kong, and Bahrain. Half of the participants in each country came from special programs or schools that represented above-average-ability students and the other half came from ordinary schools, representing average-ability students. The study revealed that the gifted students from each participating country asked more scientific questions than their average-ability peers. This finding was not found to be dependent on the respondent's gender. Furthermore, in each country the average-ability students asked more everyday life questions than did their gifted peers. The scientific and everyday life questions were very much in accord with each other in different cultures. The gifted students in all countries asked more questions about morality than did the average-ability students. The moral questions dealt with war and terrorism, which reflected the global moral concerns raised by the attacks on 9/11. Cultural differences were also found in the spiritual and religious questions asked by these preadolescents. In all the data sets, girls asked more questions of a spiritual and religious nature than boys. The Christian influence could be seen in the data for Finland and the United States. The Bahrain data clearly reflected a Muslim influence on the nature of religious questions [21].

Another study with Finnish youth $(N=316)$ explored how concepts about the future develop from preadolescence to adolescence. This study demonstrated how the number and nature of different types of question develop as students get older. The number of spiritual questions about the future increased, while the number of moral questions decreased from preadolescence to adolescence. Both preadolescent and adolescent girls asked more religious questions than did boys of the same age. The increase of spiritual questions by age can be explained by psychological developments in adolescence. The struggle for a sense of significance and purpose in life is greatest during adolescence [25].

According to Fry [25], the ultimate problem in studying adolescent psychology is to understand how the adolescent searches for and finds some measure of meaning in the present and gains wisdom for the future. This trend can be seen in the developmental process of concepts about the future, as well [22].

Kelly [26] has studied what type of questions youth ask about renewable energy. She found that questions about renewable energy most often concentrate on energy production, the economy, politics, and the environment.
The questions often seem to have a perspective on the future. Production-related questions are often about whether natural resources will run out; in economic questions people wonder whether renewable energy will be beneficial in the future; in political questions people wonder if renewable energy will decrease wars; in environmental questions people ask how using alternative energy sources will affect the environment and global warming.

\section{Data and Methods}

The participants $(N=658)$ in this study were from 32 countries in Europe $(N=420)$ and from 23 countries in Asia $(N=238)$. The countries from Europe that had the highest number of participants were Bulgaria $(N=43)$, Slovakia $(N=37)$, and Slovenia $(N=31)$. The Asian countries that provided the most students were Russia $(N=84)$, Kazakhstan $(N=44)$, and Indonesia $(N=34)$. The participants included 385 girls or $58.5 \%$ and 273 boys or $41.5 \%$. Their age varied between 16 and 19 years, the median was 17.6 years.

The data was collected by asking all the applicants to the 2011 Millennium Youth camp to present three questions regarding their chosen theme. Of the applicants, $38.7 \%(N=$ $290)$ had applied to join the renewable energy group, $38.1 \%$ $(N=286)$ to the climate change group, and 23. $2 \%(N=$ $174)$ to the water group. In addition, demographic questions were asked to find out the applicants' gender, age, and country of origin. Other informative questions were also asked, but they do not play a role in this study.

Though different research methods, such as interviews and surveys, could have been used to gain information on the types of socioscientific questions asked by the youth, we decided to obtain the research data through a less obvious way, namely, the camp applications. Firstly, the reason why the camp application was preferred over other methods of collecting data was reliability. As the camp application was not only focused on the given theme but had many other questions that the applicant had to answer, such as their own interests and school achievements, it was thought that the applicants would be less likely to think that certain types of answers were expected of them. Moreover, as the applicants were unaware that their answers would be used for research purposes, the answers, we believe, would be more authentic than if they knew that their answers would be thoroughly analyzed. In addition, as the youth filled in the application form at home, at their leisure, it could be assumed that they had more time and patience to think about their answers.

Secondly, as the youth were applying to a camp where the themes were climate change, water, and renewable energy, it could be assumed that they were familiar, at least to some extent, with these themes. Having some basic knowledge about an issue, then, allows a person to look at the issue from different perspectives. In other words, as the youth had some previous knowledge of the theme, they had the capability to present societal and moral questions, rather than just scientific questions, as proposed by Sadler and Donnelly in their research [27]. 
Thirdly, using the camp application forms enabled us to collect a large amount of data from around the world, which would have required much more work and time using other means

The data was analyzed first by a qualitative content analysis. Some participants' $(N=114,17 \%)$ questions had, for example, bad English or handwriting, and therefore these questions were impossible to interpret. These unclear questions were not included in the analysis. The final data included questions from 544 participants.

The students' questions were coded into three main categories. These categories were scientific questions, societal questions, and moral questions. Owing to the nature of the themes, some overlapping of these categories occurred. To avoid this problem, we decided to rank the categories: the ranking was done so that moral questions were ranked the highest, then societal, and last scientific questions. This means that if a question had both a scientific and a moral aspect to it, the question was ranked as moral, because the moral category was the higher rank. As it was a science camp, we hypothesized that most of the questions would be scientific, causing us to rank scientific questions the lowest. Between societal and moral questions there was no clear idea which one should be ranked higher, but as societal questions were more similar to scientific questions, and some ranking had to be made, it was decided to give moral questions the highest rank.

The interrater reliability was reasonable (ir $=.83$ ). The index was based on individual scoring of 100 students' questions by two raters. The index was calculated by the formula:

$$
\text { ir }=\frac{n \text { of rater agreements }}{n \text { of questions }} .
$$

Secondly, the data was examined using a nonparametrical statistical analysis. Three qualitative categories of questions were cross-tabulated with genders (female/male), continents (Asia/Europe), and camp themes (climate change/ renewable energy/water). The scientific significance of the relations between the variables was investigated with Pearson's chi-square.

\section{Results}

In this study, 544 scientifically gifted international high school students each presented a question they wanted an answer during the camp. The distribution of scientific, societal, and moral questions between gender, continent, and the camp's themes is seen in Table 1.

6.1. Scientific Questions. Students asked mostly scientific questions $(n=308,57 \%)$. The boys $\left(n_{\text {male }}=152,66 \%\right)$ asked more scientific questions than the girls $\left(n_{\text {female }}=156\right.$, $50 \%)\left(\chi^{2}(2)=15.872, P=.000\right)$. Furthermore, the students interested in renewable energy and resources $\left(n_{\text {renewables }}=\right.$ $142,65 \%)$ asked more scientific questions than the students interested in the other themes $\left(n_{\text {climate change }}=108,55 \%\right.$; $\left.n_{\text {water }}=58,45 \%\right)\left(\chi^{2}(4)=19.895, P=.001\right)$.
The most typical scientific questions asked by students in the renewable energy group included questions related to new methods and costs of extracting energy. The following two questions, one asked by an Asian girl and one by a European boy, are good examples.

What are some fundamentally new methods of extracting energy? (16-year-old girl from Asia)

The first specific issue in which I would like to develop my knowledge is wind power. I already know the basics of using this type of renewable energy, but I am still interested in how it works practically. What are the main benefits of it in comparison with other renewable energy sources? Also I am interested in the costs and consequences which arise from using wind power. How it is harmful for the environment? (19year-old boy from Europe)

The students in the climate change group wanted to learn the truth about the research being conducted in this area and also how to do research related to this important domain. The following questions are typical of those asked by students in this group.

I would like to learn more about research. The methods, resources, and so forth, to conduct excellent research in the field of science, specifically in the field of climate change. I consider it a very important issue. (17-year-old girl from Europe)

Climate change. What is true and what is not concerning the topic of global warming? (17-year-old boy from Asia)

The most common scientific questions related to water included topics such as the effect of global warming on water and how to define the quality of water. The following questions demonstrate this line of enquiry.

How does Global Warming affect the world's water resources? How can the resources of fresh water be rationally used? (18-year-old girl from Asia)

To learn how to define the quality of water (16-yearold boy from Asia)

6.2. Societal Questions. The second most asked type of question was societal questions $(n=125,23 \%)$. The girls asked more societal questions $\left(n_{\text {female }}=87,28 \%\right)$ than the boys $\left(n_{\text {male }}=38,17 \%\right)\left(\chi^{2}(2)=15.872, P=.000\right)$. The students in the renewable energy group $\left(n_{\text {renewables }}=32,15 \%\right)$ asked fewer societal questions than the students in the other groups $\left(n_{\text {climate change }}=56,28 \% ; n_{\text {water }}=37,29 \%\right)\left(\chi^{2}(4)=\right.$ $19.895, P=.001)$. The most typical societal questions asked by students in the renewable energy group included questions related to cooperation between countries and some economical issues in their countries. Below are some examples of these kinds of questions.

How can all countries work together to fight global warming and come to an agreement to make energy consumption between developed and developing 
TABLE 1: Frequencies and percentages of scientific, societal, and moral questions by gender, continent, and camp theme.

\begin{tabular}{|c|c|c|c|c|}
\hline & Scientific $n(\%)$ & Societal $n(\%)$ & Moral $n(\%)$ & Total $n(\%)$ \\
\hline \multicolumn{5}{|l|}{ Gender } \\
\hline Female & $156(50)$ & $87(28)$ & $72(23)$ & $315(58)$ \\
\hline Male & $152(66)$ & $38(17)$ & $39(17)$ & $229(42)$ \\
\hline \multicolumn{5}{|l|}{ Continent } \\
\hline Asia & $99(56)$ & $38(22)$ & $40(23)$ & $177(33)$ \\
\hline Europe & $209(57)$ & $87(24)$ & $71(19)$ & $367(68)$ \\
\hline \multicolumn{5}{|l|}{ Camp theme } \\
\hline Climate change & $108(55)$ & $56(28)$ & $33(17)$ & $197(36)$ \\
\hline Renewable energy and resources & $142(65)$ & $32(15)$ & $45(21)$ & $219(40)$ \\
\hline Water & $58(45)$ & $37(29)$ & $33(26)$ & $128(24)$ \\
\hline Total & $308(57)$ & $125(23)$ & $111(20)$ & $544(100)$ \\
\hline
\end{tabular}

countries more equitable? (17-year-old girl from Europe)

Bio fuels. I'm really interested in how far we would go to satisfy the demand for fuel. Bio fuels have proven to be a viable alternative for oil. Here in the Philippines, specifically in my province, some farmers in the provinces are switching into the production of bio fuels instead of rice since it is more profitable. Maybe it is not the alternative we want after all. (19-year-boy from Asia)

In the climate change group the students from Asia and Europe emphasized global aspects in finding solutions to this issue. In the following quotes from Asian students international initiatives are questioned.

I would like to learn more about climate change all over the world. Specifically I want to know how other countries relate to this problem and what actions are carried out in this regard. In the same way, I want to learn about methods of preventing and mitigating the consequences of global warming. (19-year-old boy from Asia)

During the camp, I would like to learn more about the international initiatives to reach a settlement concerning the problem of climate change. At what stage is the international cooperation in this field? Discuss the pros and cons of the existing international instruments. (17-year-old girl from Asia)

In the water group, students from Asia and Europe wanted to promote water security organizations and knowledge about the importance of water to humankind. The following examples from the data demonstrate these types of question.

I want to learn about the water security organizations and to become part of one of them. Or to create together with some supporters our own water security organization. (17-year-old girl from Asia)

I've read that many people worldwide lack access to potable water, for example, in Africa, India, and other areas. Humanity is wasting this natural wealth and using it without being aware that life with no water is unthinkable. (18-year-old boy from Europe)

6.3. Moral Questions. Only 111 students (20\%) asked a moral question. The most common themes in the moral questions asked by students were related to pollution and fresh air in the climate change group, environmental problems in the renewable energy group, and the protection of water in the water group. The Asian students asked more questions related to floods and the European students more questions related to the lack of water. The following quotes from students' answers demonstrated these lines of enquiry. The first two quotes are from the renewable energy group students.

I would like to learn more about ways to deal with global climate change both in our everyday life and on a higher level. (18-year-old girl from Europe)

I want to know more about dealing with environmental problems and emerging sources of energy. (19-year-old boy from Asia)

A European girl from the water group identified protection and cleaning of water vary important and wrote the following quote.

I want to know more about protection and means of cleaning water and ways of prevention of its pollution. (16-year-old girl from Europe)

A boy from Asia also wanted to protect water. The quote demonstrates his interest in being involved in water projects and in sharing his own ideas.

The most important and interesting issue for me is saving water. You cannot deny that water is the main thing for all living creatures. So, if we do not want our planet to die, we ought to prevent wasting priceless water. It just depends on us. That's why I have a great desire to get acquainted with the water projects of foreign scientists and to share my ideas. (18-year-old boy from Asia)

The moral questions asked by students demonstrated that they were aware of current ethical discussions in science 
education. The questions by the girls in the climate change group differed from the questions asked by the boys in the group. The girls took a more personal stand on moral issues than the boys, asking what they could do to solve the problem. The boys, in contrast, formulated the questions in a more general and impersonal way. The boys also identified the future implications of the moral questions they asked. This feature can be seen in the following examples.

How can I contribute to solving the problem of Climate Change? (17-year-old girl from Europe)

Efficient possibilities to slow down climate change, also those which may exist only in the future (16year-old boy from Europe)

\section{Concluding Remarks}

In this study, international high school students gifted in science from Europe and Asia asked scientific, societal, and moral questions related to the themes in science they wanted to study. The students were identified gifted because most of them came from scientific schools or classes, many had done well in national or international science competition, won scholarships and prizes as well as had good school grades. An equal amount of males and females applied to the camp, but males applied more to the ICT and Math group, which were not considered in this study. Females applied more to the climate change, water, and renewable resources groups. Females' interest to these themes can be explained by Sjøberg's [28] ROSE research, where he concludes that males, more often than females, think that threats to the environment are not their personal business. Females also tend to believe that they can personally influence what happens with the environment.

Our findings demonstrate that the most often asked type of question was scientific in nature. The boys asked more scientific questions than the girls. This characteristic was also evident in our earlier studies [21, 22]. The girls asked more societal question than the boys. Both boys and girls asked the same number of moral questions related to their interests. Moral questions were not as common as the other question types in our study. This feature was also evident in our earlier studies with gifted preadolescents and adolescents. In those studies we demonstrated that there tends to be fewer moral questions as students get older [22].

The students in the climate change group asked more moral questions than their peers in the water group. The nature of the moral questions asked by the girls was more personal than that of the moral questions asked by the boys. This could be explained by the ethics of care that are so typical of girls and women, who tend to care, protect, and show empathy to others in more personal ways than men [29]. The boys took a more impersonal approach to moral questions in science, but their questions often involved a future perspective. Moral questions in science need to be discussed and solved with a view to the future of humankind. Many moral issues related to climate change, renewable energy, and water require solutions that have an understanding of future needs. We need to protect, restore, and nurture our environment to be able to have a future on earth. In science education, teachers should actively discuss the moral questions that science raises with both a caring and a longterm perspective. One way to increase focus on morality and ethical issues in a science curriculum is to bring more socioscientific issues into education. Another means is to teach on the Nature of Science (NOS). Through this, students gain understanding on how science advances and what kind of decisions scientists need to make in their careers. Furthermore, students see themselves as decision makers, possibly increasing the interest to consider moral issues.

The findings of this study have been used to improve the next camp by taking moral issues more into consideration in the project works done by the youth. An example of this is the project work of the renewable energy group, where students had to consider, among other things, the use of food crops as a source of fuel.

Gifted students in science may have the best cognitive skills and logical thinking but they may lack the ethical sensitivity that is needed to solve moral dilemmas in science [15]. In a recent study on teachers' ethical sensitivity, science teachers rated their ethical sensitivity lower than teachers of other subjects [30]. This study points to the need for teachers to teach socioscientific issues and discuss moral questions in science, which might influence the future of humankind. Science teaching has a moral core like all the other subjects taught in high schools all over the world.

\section{References}

[1] Finland's Science Education Centre, "Millenium youth camp," 2012, http://www.helsinki.fi/luma/english/millenniumyouth-camp.

[2] C. Elgin, "Science, ethics and education," Theory and Research in Education, vol. 9, no. 3, pp. 251-263, 2011.

[3] K. Tirri, "Combining excellence and ethics: implications for moral education for the gifted," Roeper Review, vol. 33, no. 1, pp. 59-64, 2011.

[4] D. L. Zeidler and M. Keefer, "The role of moral reasoning and the status of socioscientific issues in science education: philosophical, psychological and pedagogical consideration," in The Role of Moral Reasoning on Socioscientific Issues and Discourse in Science Education, D. L. Zeidler, Ed., pp. 7-38, Kluwer Academic Press, Dordrecht, Netherlands, 2003.

[5] D. L. Zeidler and J. Lewis, "Unifying themes in moral reasoning on socioscientific issues and discourse," in The Role of Moral Reasoning on Socioscientific Issues and Discourse in Science Education, D. L. Zeidler, Ed., pp. 289-306, Kluwer Academic Press, Dordrecht, Netherlands, 2003.

[6] E. Chiappetta, T. Koballa, and A. Collette, Science Instruction in the Middle and Secondary Schools, Merrill, Upper Saddle River, NJ, USA, 4th edition, 1998.

[7] C. G. Gayford, "Environmental indoctrination or environmental education," Environmental Education, vol. 27, pp. 8-9, 1987.

[8] D. L. Zeidler, K. A. Walker, W. A. Ackett, and M. L. Simmons, "Tangled up in views: beliefs in the nature of science and responses to socioscientific dilemmas," Science Education, vol. 86, no. 3, pp. 343-367, 2002.

[9] Finnish National Board of Education, National Core Curriculum For Basic Education, Helsinki, Finland, 2004. 
[10] American Association for the Advancement of Science, Ed., Benchmarks For Science Literacy: Project 2061, Oxford University Press, New York, NY, USA, 1993.

[11] OECD, "OECD environmental strategy for the first decade of the 21st century," in OECD Environmental Strategy, Paris, Farnce, 2001.

[12] A. K. De, Environmental Chemistry, New Age International, New Delhi, India, 5th edition, 2005.

[13] F. Abd-El-Khalick, "Socioscientific issues in pre-collage science classroom," in The Role of Moral Reasoning on Socioscientific Issues and Discourse in Science Education, D. L. Zeidler, Ed., pp. 41-61, Kluwer Academic Publishiers, Dordrecht, The Netherlands, 2003.

[14] D. Narváez, "High-achieving students and moral judgment," Journal for the Education of the Gifted, vol. 15, pp. 268-279, 1993.

[15] K. Tirri and L. Pehkonen, "The moral reasoning and scientific argumentation of gifted adolescents," The Journal of Secondary Gifted, vol. 13, no. 3, pp. 120-129, 2002.

[16] K. Tirri, P. Nokelainen, and M. Mahkonen, "How morality and religiosity relate to intelligence: a case study of mathematically gifted adolescents," Journal of Empirical Theology, vol. 22, no. 1, pp. 70-87, 2009.

[17] K. Tirri and P. Nokelainen, "Comparison of academically average and gifted students' self-rated ethical sensitivity," Educational Research and Evaluation, vol. 13, no. 6, pp. 587-601, 2007.

[18] M. J. Bebeau, J. R. Rest, and D. Narvaez, "Beyond the promise: a perspective on research in moral education," Educational Researcher, vol. 28, no. 4, pp. 18-26, 1999.

[19] H.-G. Ziebertz and W. K. Kay, Eds., Youth in Europe I. An International Empirical Study about Life Perspectives, vol. 2 of International Practical Theology, Lit Verlag, Münster, Germany, 2005.

[20] M. Tallent-Runnels and D. Yarbrough, "Effects of the future problem solving program on children's concerns about the future," Gifted Child Quarterly, vol. 36, no. 4, pp. 190-194, 1992.

[21] K. Tirri, M. K. Tallent-Runnels, and P. Nokelainen, "A crosscultural study of pre-adolescents' moral, religious and spiritual questions," British Journal of Religious Education, vol. 27, no. 3, pp. 207-214, 2005.

[22] K. Tirri and P. Nokelainen, "Gifted students and the future," KEDI Journal of Educational Policy, vol. 3, no. 2, pp. 55-66, 2006.

[23] M. Tallent-Runnels, G. Mullen, K. Tirri, and M. Yuen, "A cross-cultural study of children's concerns about the future," A Paper Presented at the American Educational Research Association, Chicago, Ill, USA, 2003.

[24] E. Landau, Children Ask Questions about the Future, Futures, IPC Science \& Technology Press, UK, 1976.

[25] P. Fry, "The development of personal meaning and wisdom in adolescence: a re-examination of moderating and consolidating factors and influences," in The Human Quest For Meaning. A Handbook of Psychological Research and Clinical Applications, P. Wong and P. Fry, Eds., pp. 91-110, Lawrence Erlbaum Associates Publishers, Mahwah, NJ, USA, 1998.

[26] R. Kelly, Energy Supply and Renewable Resources, Infobase Publishing, New York, NY, USA, 2007.

[27] T. D. Sadler and L. A. Donnelly, "Socioscientific argumentation: the effects of content knowledge and morality," International Journal of Science Education, vol. 28, no. 12, pp. 1463 1488, 2006.
[28] S. Sjøberg and C. Schreiner, The ROSE Project. An Overview and Key Findings, University of Oslo, Oslo, Norway, 2010.

[29] K. Tirri, "The moral concerns and orientations of sixth- and ninth-grade students," Educational Research and Evaluation, vol. 9, no. 1, pp. 93-108, 2003.

[30] E. Kuusisto, K. Tirri, and I. Rissanen, "Finnish teachers'ethical sensitivity," Education Research International. In press. 


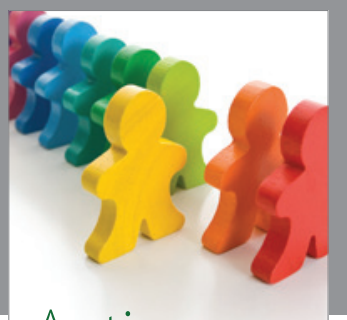

Autism

Research and Treatment
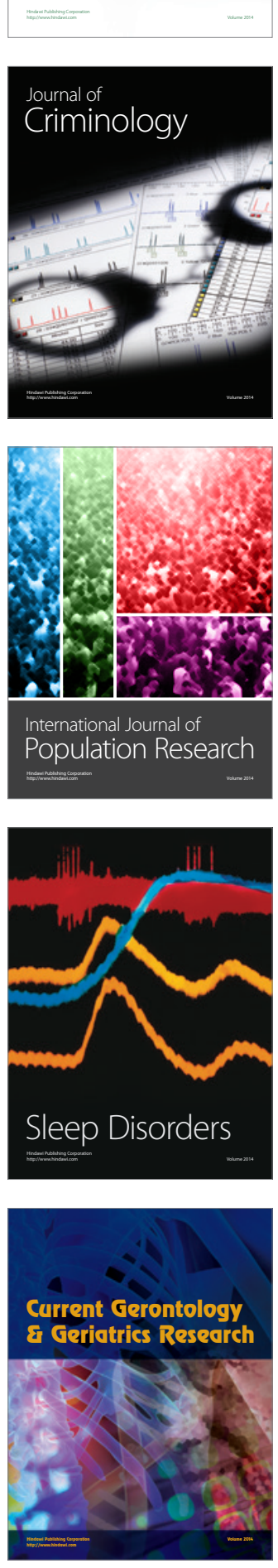
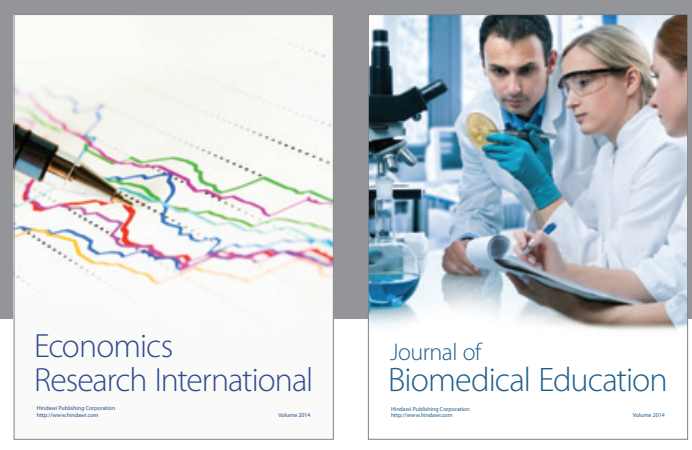

Journal of

Biomedical Education

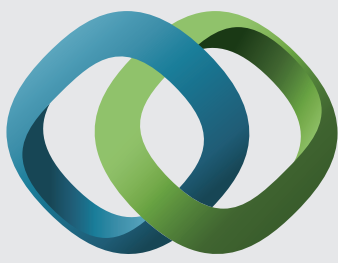

\section{Hindawi}

Submit your manuscripts at

http://www.hindawi.com
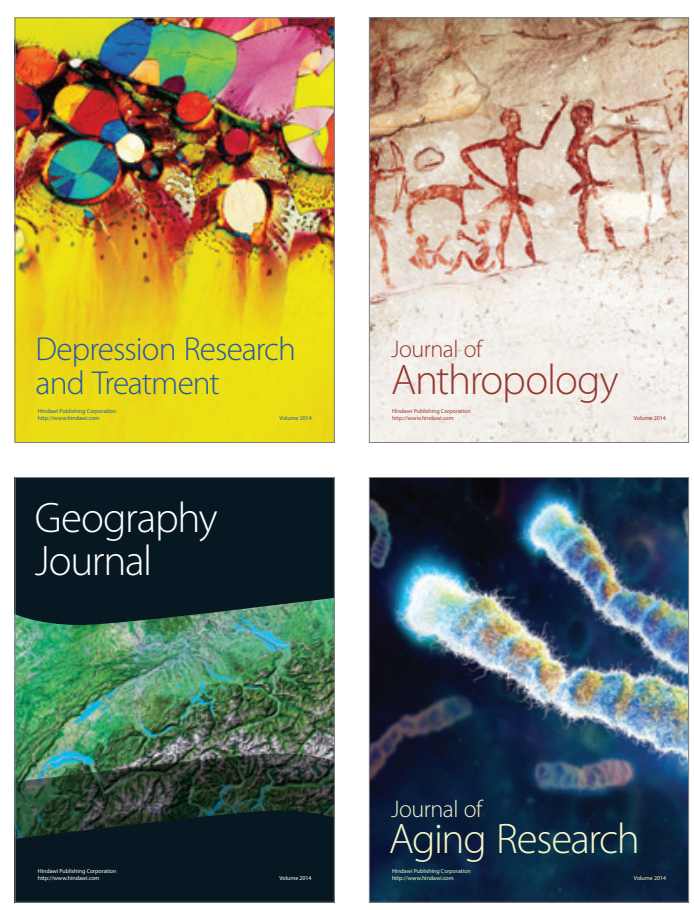

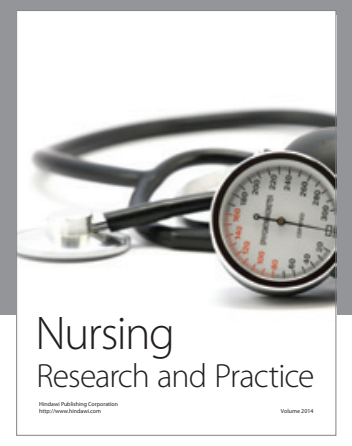

Nursing

Research and Practice

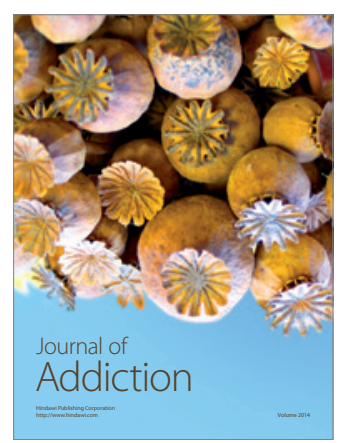

Child Development

Research

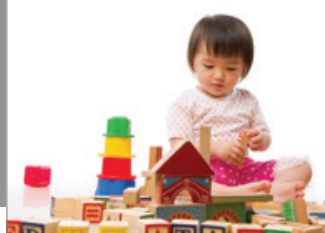

迥
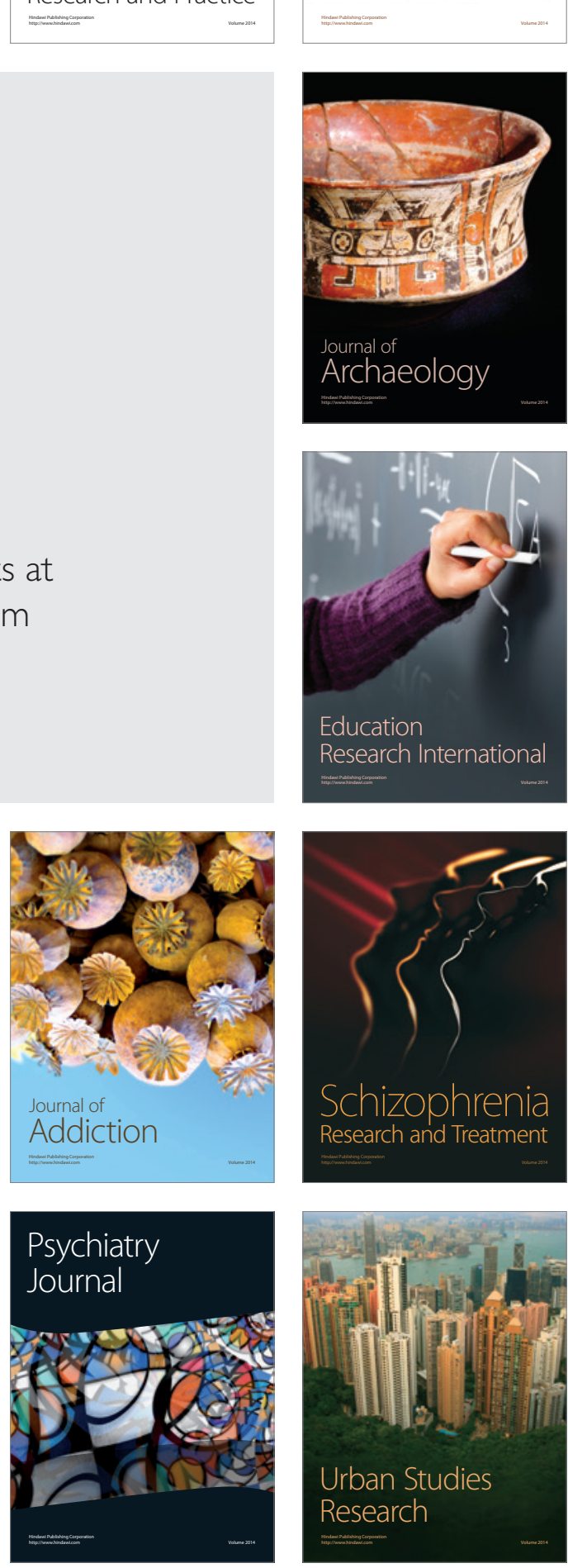